\title{
CARACTERIZAÇÃO DE SOLOS QUANTO A AFETAÇÃO POR SAIS NA BACIA DO RIO CABUGÍ - AFONSO BEZERRA-RN
}

\author{
Djeson Mateus A. da Costa ${ }^{1}$ \\ José Simplício de Holanda ${ }^{2}$ \\ Orlando Augusto de Figueiredo Filho ${ }^{3}$ \\ ${ }^{1}$ Professor do CEFET-RN, Mestre em Geociências. djeson@cefetrn.br \\ ${ }^{2}$ Engenheiro Agrônomo, Pesquisador da Embrapa, Doutor em Solos e Nutrição de Plantas. \\ ${ }^{3}$ Geólogo, Professor da UFRN, Doutor em Geologia Estrutural.
}

\section{RESUMO}

O presente trabalho objetiva avaliar os solos de uma área de 40,5 ha, situada no Município de Afonso Bezerra-RN, para fins agrícolas, por meio da determinação de $\mathrm{pH}$ do solo e do extrato saturado do solo; dos índices de cátions trocáveis e solúveis e, a partir destes, estimar o grau de afetação por meio da capacidade de troca de cátions (CTC), porcentagem de sódio trocável (PST) e da razão de adsorção de sódio (RAS), existentes nos aluviões situados em parte da Bacia do Rio Cabugi, no Município de Afonso Bezerra-RN. Além dessas propriedades químicas, são avaliadas as seguintes propriedades físicas: velocidade de infiltração da água no solo, a granulometria (porcentagens de areia, silte e argila) e a condutividade elétrica do extrato saturado do solo $\left(\mathrm{CE}_{\mathrm{ES}}\right)$. A avaliação dessas propriedades foi feita através de análises, em laboratório, de amostras de solo coletadas em quatro camadas, nas profundidades de 0-30 cm, 31-60 cm, 61-90 cm e 91-150 cm.

Palavras-chave: Solo, água, salinidade e irrigação.

\section{PHYSICAL-CHEMICAL CHARACTERIZATION OF SOILS OF RIO CABUGÍ'S BASIN IN THE MUNICIPAL DISTRICT OF AFONSO BEZERRA-RN}

\begin{abstract}
The present work objectifies to evaluate the soils of an area of 40,5 ha. placed in the Municipal district of Afonso Bezerra-RN, for agricultural ends through the determination of $\mathrm{pH}$ of the soil and of the saturated extract of the soil; of the indexes of exchangeable and soluble cátions and, starting from these, to esteem the affectation degree through capacity of exchange of cátions (CTC), exchangeable sodium percentage (ESP) and reason of adsorção of sodium (SAR), existent in them alluviums placed partly of Rio Cabugí's Basin, in the Municipal district of Afonso Bezerra-RN. Besides those properties chemistries they are appraised the following physical properties: speed of infiltration of the water in the soil, the granulometria (percentages of sand, silte and clay) and electric condutividade of the saturated extract of the soil $\left(\mathrm{CE}_{\mathrm{ES}}\right)$. The evaluation of these properties was made through analyses in laboratory of soil samples collected in four layers, in the depths of 0-30 $\mathrm{cm}, 31-60 \mathrm{~cm}, 61-90 \mathrm{~cm}$ and $91-150 \mathrm{~cm}$.
\end{abstract}

Keywords: Soil, water, salinity and irrigation. 


\section{CARACTERIZAÇÃO DE SOLOS QUANTO A AFETAÇÃO POR SAIS NA BACIA DO RIO CABUGÍ - AFONSO BEZERRA-RN}

\section{INTRODUÇÃO}

O desenvolvimento de agricultura sustentável é, hoje, mundialmente requerido para que se possa atender às necessidades alimentícias da população que cresce continuamente. As manutenções da fertilidade e da umidade necessárias ao solo são os dois mais importantes fatores para uma produção agrícola sustentável (Needham, 1984).

A prática da irrigação, em muitas situações, é a única maneira de garantir a produção agrícola, principalmente em regiões tropicais de clima quente e seco, como é o caso do Semi-árido do Nordeste Brasileiro, onde ocorre déficit hídrico para as plantas, devido à taxa de evapotranspiração exceder à de precipitação durante a maior parte do ano (Holanda e Amorim, 1997; Hanson et al.,1993). Segundo Yap-Salinas \& Brito (1982), o Rio Grande do Norte talvez seja o estado do Nordeste com o mais alto índice de zonas semi-áridas, atingindo aproximadamente $92 \%$ de seu território. Nessa região, sem manejo adequado da irrigação, a salinização do solo é inevitável (Holanda \& Amorim, 1997). Por isso, é de fundamental importância, no manejo desses solos, o perfeito conhecimento do momento de irrigar, além do nível de salinidade tolerada pela cultura a ser irrigada e da qualidade e quantidade de água a ser adicionada através da irrigação.

A salinidade e a sodicidade nos solos afetados por sais representam a maior ameaça para a agricultura em escala global. A primeira afeta principalmente a absorção de água pelas plantas, devido à redução do potencial osmótico da solução do solo, enquanto que a segunda afeta a estrutura do solo e, indiretamente, a disponibilidade da água (Bernardo, 1995). A presença de sais no solo pode também provocar problemas de toxicidade para as plantas. O conjunto desses problemas resultará na diminuição da produção agrícola.

Segundo Robinson (1953), alguns constituintes presentes no solo podem provocar a sua infertilidade. Eles se agrupam em três categorias: ácidos existentes no solo; compostos metálicos venenosos; e sais solúveis (incluindo os álcalis). Para Eilers (1995), a salinização do solo ocorre em lugares onde as seguintes condições coexistem: presença de sais solúveis no solo; alto nível do lençol d’água; e alta velocidade de evaporação. Dentre os fatores que controlam a ocorrência, a extensão e o nível de salinidade do solo incluem-se: os de longa duração (materiais formadores do solo, topografia, drenagem do solo, hidrologia das águas subterrâneas e clima regional) e os de curta duração (precipitação, evaporação, uso da terra e práticas de cultivo).

No Brasil, os principais problemas de salinização estão surgindo nos projetos de irrigação, notadamente nos projetos públicos situados no "Polígono das Secas". As principais causas disso relacionam-se à falta de drenagem associada à baixa eficiência da irrigação por superfície, conduzida na maioria dos projetos, e não à qualidade da água usada (Bernardo, 1995).

Segundo Bernardo (1995), o Laboratório de Salinidade dos Estados Unidos da América adota quatro categorias para a classificação dos solos afetados por sais: solos normais; solos salinos; solos salino-alcalino ou alcalino-sódico; e solo alcalino ou sódico. Os 
parâmetros adotados para essa classificação foram os mesmos propostos por Richards (1974).

Os solos salinos apresentam CEES superior a 4,0 dS.m ${ }^{-1}$ (deci-siemens.m ${ }^{-1}$ ) e sua recuperação pode ser feita através da lixiviação dos sais (Bernardo, 1995). Por outro lado, os solos sódicos apresentam PST superior a 15\% e sua melhoria poderá ocorrer com a aplicação de condicionadores (Bernardo, 1995) ou através da subsolagem (Holanda, 2000).

O presente trabalho teve como objetivos a caracterização de solos quanto à afetação por sais, às margens do Rio Cabugi, Município de Afonso Bezerra-RN, delimitando as áreas afetadas e/ou que apresentem riscos em potencial de salinização e sodificação.

\section{MATERIAIS E MÉTODOS}

\section{Características da área}

A área estudada compreende uma faixa de terra, de aproximadamente 40,5 ha, situada à margem do Rio Cabugi, no Município de Afonso Bezerra-RN, conhecida pelo nome de Roçado do Meio, conforme representada pela Figura 1. O local de estudo é uma das muitas faixas de terras do Município, onde, no período de estiagem, é possível se desenvolver culturas irrigadas. Os cultivares mais semeados nessa área são: melancia, melão, banana leite e acerola.

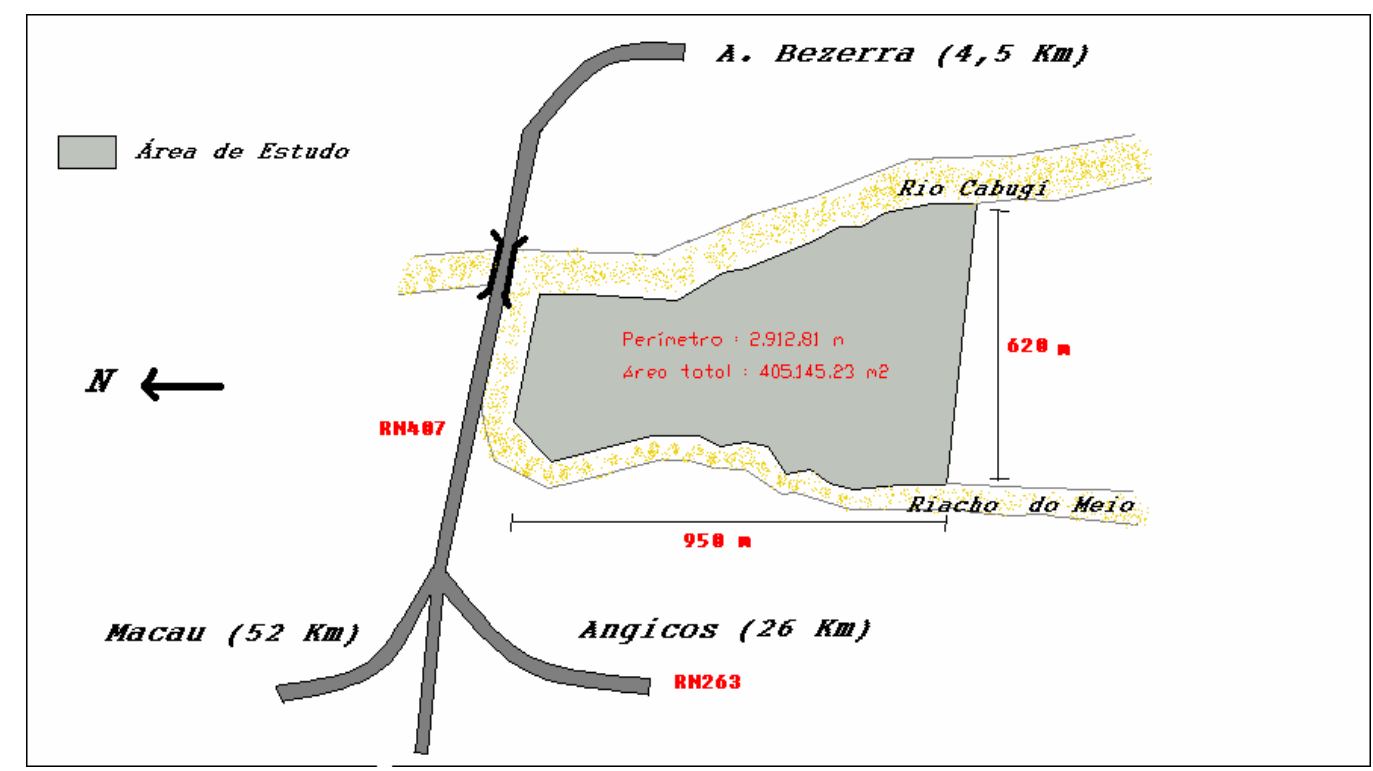

Figura 1. Localização, contorno e dimensões da área estudada.

O Município de Afonso Bezerra está localizado na micro-região de Angicos-RN, na zona homogênea do litoral Norte, 5²9’54” Sul; 36³0'20” Oeste, numa altitude média de $62 \mathrm{~m}$ acima do nível do mar. O clima predominante é semi-árido, apresentando precipitação média anual de 516,5 mm, com período das chuvas concentrado entre março e abril de cada ano, com temperatura média $27^{\circ} \mathrm{C}$ e umidade relativa média anual de $70 \%$ (IDEMA, 1999). 
Segundo dados da SERHID (1997), o déficit de precipitação acumulada nos últimos 21 anos, em relação à média de longo período (MLP) para a região, atinge a cifra de 3.124 mm.(ano) ${ }^{-1}$.

No Município, predomina a vegetação de Caatinga hipoxerófila e hiperxerófila e os solos, na maior parte, são cambissolos eutróficos e, às margens dos rios e riachos, verifica-se a presença de solos aluviais eutróficos, que apresentam relevo plano a suavemente ondulado, caracterizando feição de chapada (IDEMA, 1999).

A área do município abrange terrenos tanto sobre o Embasamento Cristalino quanto sobre a Bacia Potiguar (Carvalho, 1973; IBGE, 1985). Situa-se, ainda, áreas da Bacia Hidrográfica Piranhas-Açu, apresentando hidrologia com alguns rios, riachos e açudes de pequeno porte (IDEMA, 1999). Além disso, possui águas subterrâneas provenientes dos aqüíferos regionais Jandaíra, Açú e Aluvião (SERHID, 1998; IDEMA, 1999).

\section{Condução da pesquisa}

Os trabalhos iniciaram-se com a seleção e delimitação da área a ser estudada, sendo escolhida uma faixa de terras que há algum tempo vinha sendo irrigada e que, em alguns setores, já apresentava problemas relativos à redução de produção.

A área estudada foi subdividida em três setores: uma área ainda virgem (setor B), sendo o espaçamento dos pontos de amostragem numa malha com distância de 100 m, localizandose ao Norte do terreno; uma área central (setor A), na qual se deu maior densidade de amostragem por ser esta a que há mais tempo vem sendo irrigada, distando-se os pontos de amostragem de 50m; e uma área no extremo Sul (setor C), na qual se inicia atualmente a prática da irrigação, ficando seus pontos de amostragem eqüidistantes de $100 \mathrm{~m}$.

Os parâmetros de solo avaliados compreenderam $\mathrm{pH}$; salinidade, CTC; sodicidade PST; velocidade de infiltração de água no solo; e os teores de íons solúveis (Ca, Mg, $\mathrm{Na}, \mathrm{K}$ e $\mathrm{Cl})$.

Para a avaliação da variação de sais no perfil do solo, foram feitas amostragens em cada ponto experimental, utilizando-se trado manual ou tubo coletor, nas profundidades: 0-30 $\mathrm{cm}$; 31-60 cm; 61-90 cm; e 91-150 cm. Todas as amostras de solo foram analisadas no Laboratório de Solos da Empresa de Pesquisa Agropecuária do Rio Grande do Norte (EMPARN). Os métodos aplicados, nas análises laboratoriais de solo, seguiram às normas adotadas pela EMBRAPA (1997). O método aplicado, em campo, para a determinação da velocidade de infiltração da água no solo é do Infiltrômetro de Anel (Bernardo, 1995).

Os resultados obtidos foram agrupados, considerando-se, para efeito de afetação por sais na área, os maiores valores de $\mathrm{CE}_{\mathrm{ES}}$ e PST, determinados em qualquer profundidade do perfil de 0 a $150 \mathrm{~cm}$ e comparados com os padrões de referência (Richards, 1974; Oliveira, 1997). De posse dessas informações, a área foi mapeada em detalhe, com os setores afetados por sais representados por cores diferenciadas: setor hachurado em cinza-claro possui valores de $\mathrm{CE}_{\mathrm{ES}}$ inferiores a 2,00 dS/m ou PST menor que 8,0\%; em cinza-escuro apresenta $\mathrm{CE}_{\mathrm{ES}}$ no intervalo de 2,00 a $4,00 \mathrm{dS} / \mathrm{m}$ e PST entre $8 \%$ e $15 \%$; e em preto, valores de $\mathrm{CE}_{\mathrm{ES}}$ superiores a 4,00 dS/m e de PST superiores a 15\% (Figuras 2 e 4). 


\section{RESULTADOS E DISCUSSÃO}

\section{Salinidade - Condutividade elétrica no extrato saturado}

A CE $E_{E S}$ média nas diversas camadas apresentou acentuada diminuição com a profundidade do solo, conforme Quadro 1. Em geral, em época de chuva, o nível de salinidade $\left(\mathrm{CE}_{\mathrm{ES}}\right)$ aumenta com a profundidade. Porém, o que se observou foi exatamente uma inversão no perfil de salinidade do solo, causado pelo fluxo ascendente, por efeito da capilaridade, atendendo a evapotranspiração, no período de maior estiagem na região (julho à novembro).

Quadro 1: Variação da $\mathrm{CE}_{\mathrm{ES}}$ média nas diversas camadas do solo.

\begin{tabular}{|l|c|c|c|c|}
\hline Camada $(\mathrm{cm})$ & $0-30$ & $31-60$ & $61-90$ & $91-150$ \\
\hline $\mathrm{CE}_{\mathrm{ES}}\left(\mathrm{dS} . \mathrm{m}^{-1}\right)$ & 2,40 & 1,86 & 1,45 & 1,35 \\
\hline $\mathrm{Cl}^{-}\left(\mathrm{mmol} \cdot \mathrm{L}^{-1}\right)$ & 18,07 & 15,79 & 12,41 & 10,95 \\
\hline $\mathrm{RAS}$ & 4,10 & 3,53 & 3,22 & 3,39 \\
\hline
\end{tabular}

Foi observada uma estreita relação da $\mathrm{CE}_{\mathrm{ES}}$ com a textura do solo. As camadas de classes texturais franco foram as que mais acumularam sais. Tal fato é conseqüência do maior teor de argila na respectiva classe. Através do Quadro 2 pode-se verificar o comportamento da $\mathrm{CE}_{\mathrm{ES}}$ média, de acordo com a textura do solo analisado.

Quadro 2: Variação da $\mathrm{CE}_{\mathrm{ES}}$ média em função das classes texturais.

\begin{tabular}{|c|c|c|c|}
\hline Classe textural & CE $_{\mathrm{ES}}$ & PST & CTC \\
\hline Areia & 0,88 & 3,11 & 4,10 \\
\hline Areia Franca & 1,64 & 4,53 & 6,06 \\
\hline Franco Arenoso & 1,72 & 5,73 & 9,44 \\
\hline Franco & 2,65 & 6,29 & 14,82 \\
\hline
\end{tabular}

Ao analisar os valores para a $\mathrm{CE}_{\mathrm{ES}}$ do solo nos diferentes setores da área, constatou-se que essas magnitudes foram sempre superiores na área central (setor A), na qual há mais tempo se pratica agricultura irrigada. Tal ocorrência foi observada em todas as camadas de terras amostradas, caracterizando a indução da salinização do solo devido à irrigação. Observa-se que a área com problema de salinidade (em preto, com $\mathrm{CE}_{\mathrm{ES}}>4,00 \mathrm{dS} . \mathrm{m}^{-1}$ ) já representa uma considerável superfície da área em estudo (Figura 2). 


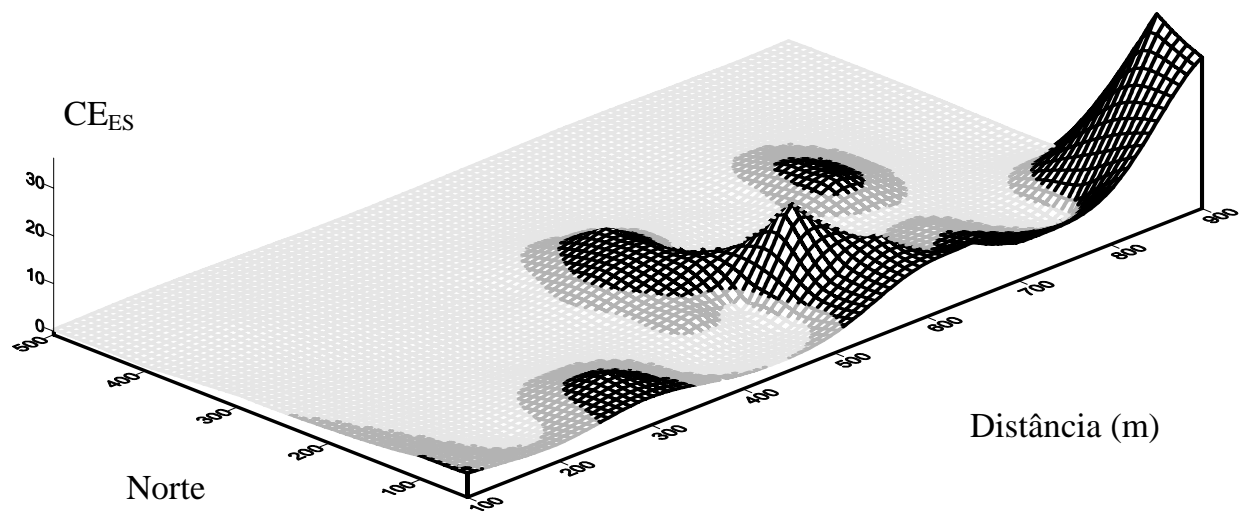

Legenda:

Cinza-claro: $\mathrm{CE}<2,00 \mathrm{dS} . \mathrm{m}^{-1}$

Cinza-escuro: 2,00 < CE < 4,00 dS. ${ }^{-1}$

Preto: $\mathrm{CE}>4,00 \mathrm{dS} . \mathrm{m}^{-1}$

\section{Figura 2. Setores pertencentes à área em estudo que já se encontram afetados por sais.}

O processo de salinização na referida área deve-se, principalmente, ao desenvolvimento dos ciclos de acumulação de sais nos solos: o ciclo dos deltas e o antropogênico (Oliveira, 1997). No primeiro caso, o processo é favorecido pelas condições edafoclimáticas. Sendo assim, a presença, na região, de clima semi-árido com drenagem deficiente e águas disponíveis para irrigação com altos teores de sais, classificadas como $\mathbf{C}_{\mathbf{3}} \mathbf{S}_{\mathbf{1}} \mathbf{T}_{\mathbf{3}}$ (87,50\% das amostras) e $\mathbf{C}_{\mathbf{4}} \mathbf{S}_{\mathbf{1}} \mathbf{T}_{\mathbf{3}}$ (12,50\% das amostras), favorecem a acumulação dos sais no solo. E, no segundo caso, a salinização do solo é induzida devido ao emprego de técnicas de irrigação (alagamento, aspersão, uso da irrigação em horário de maior incidência solar etc.), que na realidade favorecem a ascensão da água e posterior evaporação ao atingir a superfície do solo, causando a precipitação dos sais dissolvidos nela.

\section{Velocidade de infiltração da água}

Verificou-se que o tempo gasto na infiltração da água no solo do setor há mais tempo irrigado foi maior que a do setor nunca antes irrigado, e do que a do setor recentemente irrigado. Tal fato caracteriza o processo de degradação induzida do solo, devido ao uso da irrigação. Isso muitas vezes ocorre como conseqüência do aumento da quantidade de sais de sódio adicionados ao solo pela água utilizada na irrigação, o que provoca a dispersão da argila e a conseqüente diminuição da porosidade.

De acordo com o descrito no parágrafo anterior, observa-se, através do Quadro 3, que a coluna d’água infiltrada, no setor há mais tempo irrigado, apresentou uma redução de aproximadamente 76,85\% em relação à infiltração no setor nunca antes irrigado. 
Quadro 3: Variação da infiltração acumulada da água nos diversos setores da área estudada.

\begin{tabular}{|c|c|c|c|}
\hline $\begin{array}{c}\text { Tempo de infiltração } \\
\text { (min) }\end{array}$ & $\begin{array}{c}\text { Coluna d'água } \\
\text { infiltrada no setor A } \\
(\mathrm{cm})\end{array}$ & $\begin{array}{c}\text { Coluna d'água } \\
\text { infiltrada no setor B } \\
(\mathrm{cm})\end{array}$ & $\begin{array}{c}\text { Coluna d'água } \\
\text { infiltrada no setor C } \\
(\mathrm{cm})\end{array}$ \\
\hline 5 & 1,5 & 3,5 & 3,5 \\
\hline 10 & 2,3 & 7,0 & 5,0 \\
\hline 20 & 3,5 & 12,5 & 7,4 \\
\hline 30 & 4,9 & 17,9 & 9,4 \\
\hline 40 & 5,6 & 23,0 & 11,2 \\
\hline 50 & 6,8 & 27,9 & 13,1 \\
\hline 60 & 7,8 & 32,6 & 14,9 \\
\hline 70 & 8,8 & 37,7 & 16,6 \\
\hline 80 & 9,7 & 41,9 & 18,1 \\
\hline
\end{tabular}

A: há mais tempo irrigado; B: nunca antes irrigado; C: há pouco tempo irrigado.

Observou-se, ainda, tendência de diminuição da taxa de infiltração da água no solo com o aumento do tempo de aplicação, tanto para os setores há muito tempo irrigados como para os demais (Figura 3). Tal fato pode ser justificado devido ao aumento da umidade e, também, a diminuição da quantidade de espaços vazios no solo, o que vem, conseqüentemente, dificultar o transporte de água através do mesmo, conforme Withers \& Vipond (1974) e Bernardo (1995).

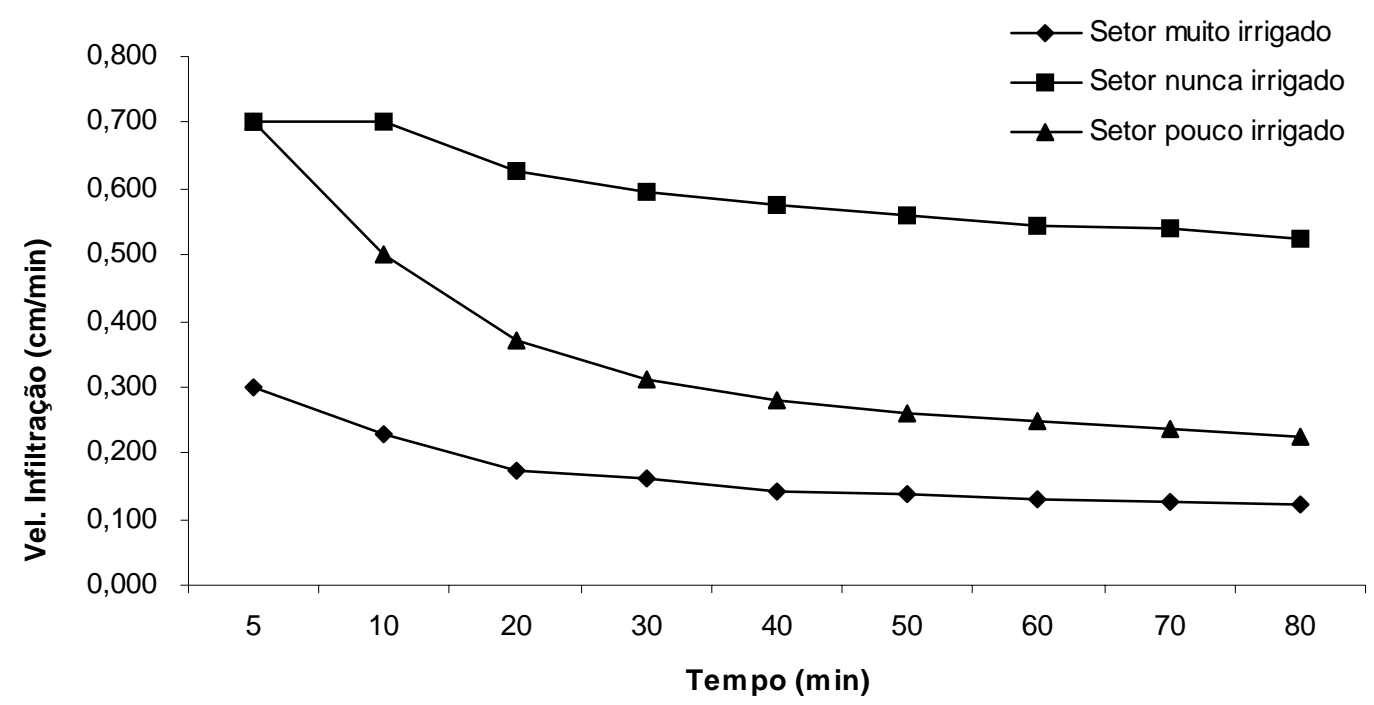

Figura 3: Comportamento da taxa de infiltração da água nos diversos setores da área em estudo em função do tempo de aplicação.

Considerando-se que a taxa média de infiltração d'água na área nunca antes irrigada -setor B - 0,596 cm.(min) ${ }^{-1}$ ou 35,76 cm.h $\mathrm{h}^{-1}$ - encontra-se no intervalo de 9,18 cm.h ${ }^{-1}$ e 37,92 $\mathrm{cm} . \mathrm{h}^{-1}$, variabilidade característica das aluviões, pode-se classificar esse solo como de permeabilidade moderadamente rápida a rápida e de alta permeabilidade, segundo as classes propostas, respectivamente, por Scherer et al. (1996) e Bernardo (1995). 
Na área há mais tempo irrigada (setor A), a taxa média de infiltração foi inferior se comparada à da área referida no parágrafo anterior. Seu valor médio foi de 0,169 $\mathrm{cm}$.(min.) $)^{-1}$ ou $10,14 \mathrm{~cm} . \mathrm{h}^{-1}$, podendo-se atribuir essa característica ao excesso de sais acumulados no solo devido à má qualidade da água utilizada na irrigação $\left(\mathrm{CE}_{\mathrm{A}}=2,26\right.$ $\mathrm{dS} \cdot \mathrm{m}^{-1}$, condutividade elétrica da água), a drenagem e ao manejo inadequado do terreno.

\section{Potencial de hidrogêniônico do solo (pH)}

Os valores médios do pH do solo, obtido através da relação mássica solo - água (1:2,5), e do extrato saturado do solo, para as diversas camadas amostradas, não apresentaram grandes variações. $\mathrm{O}$ pH do solo apresentou oscilação média, nas diversas camadas, de 7,35 a 7,49, enquanto o $\mathrm{pH}$ do extrato saturado variou de 7,10 a 7,28, o que indica solo ligeiramente alcalino.

\section{Cátions trocáveis do solo}

Os teores de cálcio e magnésio trocáveis apresentaram valores médios mais elevados nas camadas mais inferiores. Em todas as camadas do solo, os índices de magnésio foram inferiores aos de cálcio, sendo, aproximadamente, a metade deste (Quadro 4). Os maiores valores para os teores desses cátions trocáveis foram encontrados nas camadas do solo com texturas argilosas e siltosas.

\section{Quadro 4: Valores médios para o teor de cálcio e magnésio trocável nas camadas do} solo.

\begin{tabular}{|c|c|c|}
\hline Camadas do solo & Ca $\left(\mathrm{cmol} \cdot \mathrm{kg}^{-1}\right)$ & $\mathrm{Mg}\left(\mathrm{cmol}^{-1} \mathrm{~kg}^{-1}\right)$ \\
\hline $0-30 \mathrm{~cm}$ & 5,08 & 2,19 \\
\hline $31-60 \mathrm{~cm}$ & 5,26 & 2,26 \\
\hline $61-90 \mathrm{~cm}$ & 5,63 & 2,56 \\
\hline $91-150 \mathrm{~cm}$ & 5,93 & 2,70 \\
\hline
\end{tabular}

Os maiores valores para potássio trocável foram encontrados nas camadas superficiais, sendo esses valores sempre inferiores aos de magnésio. Com um valor médio de 0,28 $\mathrm{cmol}_{\mathrm{c} .} \mathrm{kg}^{-1}$ (centimol. $\mathrm{kg}^{-1}$ ) de solo, representando aproximadamente 3,05\% da CTC, o potássio encontrado no solo da área estudada apresenta-se em concentração compatível para o crescimento das plantas. Segundo Boyer (1973), citado por Malavolta (1976), os valores de potássio trocável são limitantes quando representam porcentagens inferiores a 2,0\% - 2,5\% da CTC.

Na camada de 0-30 cm, a PST do solo mostrou-se mais elevada que nas diversas camadas, caracterizando, portanto, como a camada crítica. Outra observação importante é que, no setor há mais tempo irrigados (setor A), os níveis alcançados para a PST do solo, em todas as camadas amostradas, também, foram superiores que aos dos outros setores (setores B e C).

Na Figura 4, pode-se visualizar o comportamento da PST do solo ao longo da área estudada. Percebe-se que uma considerável faixa de terras, dentro da área estudada, já se apresenta com caráter sódico, necessitando, assim, da recuperação e/ou redução da PST. Os valores da PST cotados na cor cinza-claro indicam serem inferiores a 8\%; na cor cinza- 
escuro, entre 8 e 15\% (ambos representando solo não sódico); e, em preto, superiores a 15\% (indicando solo sódico).

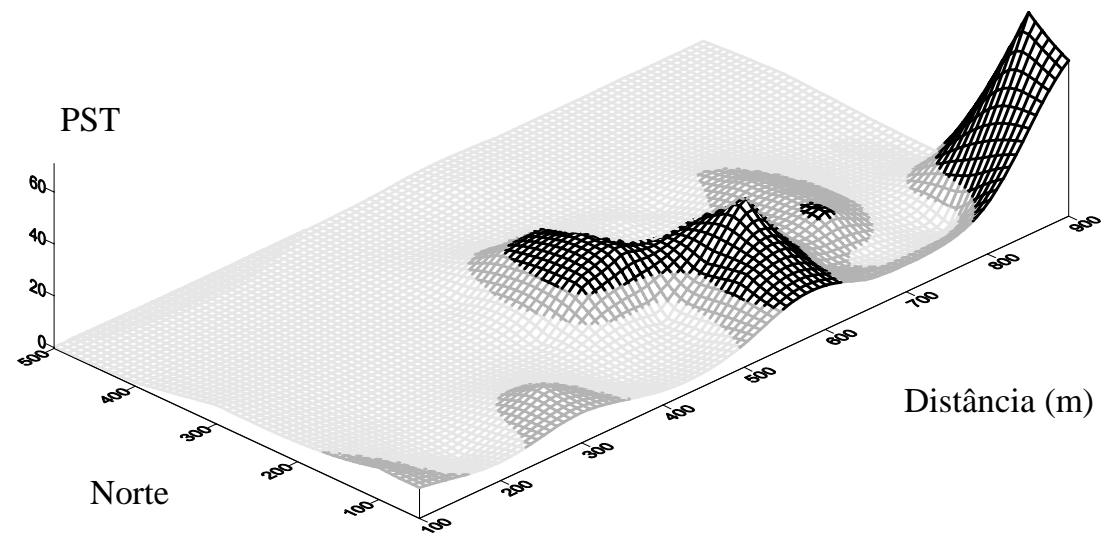

Legenda:

Cinza-claro: CE $<2,00 \mathrm{dS} . \mathrm{m}^{-1}$

Cinza-escuro: $2,00<\mathrm{CE}<4,00 \mathrm{dS} . \mathrm{m}^{-1}$

Preto: CE > 4,00 dS.m

Figura 4: Setores da área em estudo que apresentaram problemas de sodicidade na camada de $0-150 \mathrm{~cm}$.

Vale salientar que, se os complexos trocáveis contêm quantidades elevadas de sódio, o solo pode dispersar-se, causando aeração deficiente e baixa disponibilidade de água, situação comum em solos de textura argilosa (Mc George \& Breazeale, 1938; citado por Richards, 1974).

Pode-se, pelo Quadro 2, verificar a variação média da PST e CTC do solo amostrado em função da sua respectiva textura. Os maiores valores da CTC para o solo amostrado foram apresentados nas camadas mais profundas, ao mesmo tempo em que esses valores associaram-se às texturas Franco e Franco-Arenoso. As camadas com essas texturas apresentam, também, maiores valores para PST, e correspondem às com maior teor de argila.

\section{Íons solúveis}

Em se tratando dos cátions $\mathrm{Ca}^{+2}$ e $\mathrm{Mg}^{+2}$ solúveis, a variação dos níveis de concentração nas diversas camadas do solo foi exatamente o inverso da variação ocorrida nos teores de $\mathrm{Ca}^{+2}$ e $\mathrm{Mg}^{+2}$ trocáveis. Dessa forma, enquanto as concentrações de $\mathrm{Ca}^{+2}$ e $\mathrm{Mg}^{+2}$ trocáveis aumentaram com a profundidade, no extrato saturado as concentrações de $\mathrm{Ca}^{+2}$ e $\mathrm{Mg}^{+2}$ solúveis diminuíram. Em todo caso, as concentrações de magnésio foram sempre inferiores às de cálcio.

As concentrações de sódio e potássio no extrato saturado do solo variaram de forma bem perceptível nas diversas camadas do solo. Ocorreu uma redução nos valores das concentrações desses elementos na camada de $0-30 \mathrm{~cm}$, com $\left[\mathrm{Na}^{+}\right]=12,86 \mathrm{mmol}_{\mathrm{c} .} \mathrm{L}^{-1}$ e $\left[\mathrm{K}^{+}\right]=0,45 \mathrm{mmol}_{\mathrm{C}} \cdot \mathrm{L}^{-1}$, para a de $91-150 \mathrm{~cm}$, com $\left[\mathrm{Na}^{+}\right]=6,23 \mathrm{mmol}_{\mathrm{C} \cdot} \mathrm{L}^{-1}$ e $\left[\mathrm{K}^{+}\right]=0,20$ 
$\operatorname{mmol}_{\mathrm{c} .} \mathrm{L}^{-1}$. Isso representa uma diminuição de mais de $50 \%$. Tal fato não ocorreu com as concentrações de sódio e potássio trocáveis.

Constatou-se uma diminuição na concentração de íons cloreto nas camadas mais profundas. Nesse caso, a camada mais superficial do solo $(0-30 \mathrm{~cm})$ apresentou uma $\left[\mathrm{Cl}^{-}\right]=$ $18,07 \mathrm{mmol}_{\mathrm{c} .} \mathrm{L}^{-1}$, enquanto que na mais profunda $(91-150 \mathrm{~cm})$ essa concentração caiu para $10,95 \mathrm{mmol}_{\mathrm{C}} / \mathrm{L}$, representando uma redução de quase $50 \%$ (Quadro 1). Esse fato relacionase com a solubilidade do íon cloreto em água e, nesse caso, é provável que, devido à ascensão capilar, a solução do solo, rica em íons cloreto, tenha subido para a camada mais superficial e, em seguida, a água tenha se evaporado provocando conseqüentemente a precipitação de cloreto $\left(\mathrm{NaCl}, \mathrm{CaCl}_{2} \ldots\right)$.

Os valores mais elevados para a RAS (Quadro 1) dos solos analisados foram determinados nas camadas mais superficiais do solo e estavam situados exatamente nos setores há mais tempo irrigados e identificados em todas as camadas amostradas. Constatou-se, ainda, que $7,58 \%$ da área estudada apresentava valor para a RAS superior a 13. Valores elevados para esse parâmetro trazem como conseqüência o endurecimento do solo, havendo a diminuição da capacidade de retenção de água e também maior dificuldade para a penetração das raízes das plantas.

Na Figura 5 estão expressos os valores médios determinados, separadamente, da razão de sódio trocável (RST) e da RAS. Nela observa-se que a primeira sempre assume valores inferiores à segunda. Pela linha de tendência, nota-se que os valores da RST apresentam um comportamento exponencial e de forma crescente em relação aos da RAS. Essa tendência exponencial foi obtida para valores da RAS inferiores a 15. No entanto, uma relação linear foi obtida por Richards (1974) quando os valores da RAS eram bem superiores a esse limite.

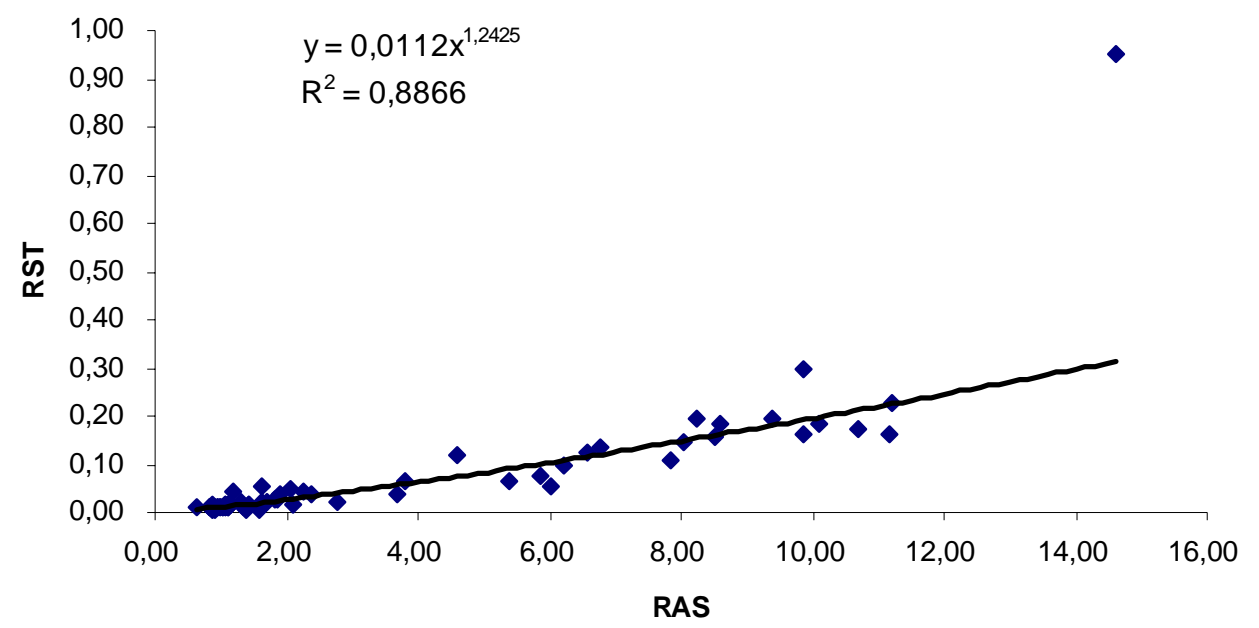

Figura 05: Variação da Relação de Sódio Trocável (RST) com a Relação de Adsorção de Sódio do solo (RAS).

Usando os dados da Figura 5 pode-se obter a relação entre a PST e a RAS, a qual se estabelece pela equação: 


$$
P S T=\frac{100 \cdot\left(0,0112 \cdot R A S^{1,2425}\right)}{\left[1+\left(0,0112 \cdot R A S^{1,2425}\right)\right]},
$$

onde o coeficiente de determinação $\left(\mathrm{R}^{2}\right)$ expressa que $88,66 \%$ da variabilidade dos valores da RST é devido a RAS, implicando em apenas $11,44 \%$ à outros fatores. No entanto, pela tendência linear obtida por Richards (1974), a relação entre a PST e a RAS foi estabelecida pela equação:

$$
P S T=\frac{100 \cdot(-0,0126+0,01475 \cdot R A S)}{[1+(-0,0126+0,01475 \cdot R A S)]}
$$

Nesse caso, o coeficiente de determinação $\left(\mathrm{R}^{2}\right)$ fornece que $85,2 \%$ da variabilidade dos valores da RST é devido a RAS, restando 14,8\% à outros fatores.

A caracterização do solo foi feita segundo os parâmetros adotados por Richards (1974); Scherer, et al. (1996), para classificar os solos quanto à salinidade e sodicidade. Na quantificação dos setores afetados por sais foram estabelecidos os seguintes valores:

- 06 pontos de amostragem: $\mathrm{CE}_{\mathrm{ES}}>4 \mathrm{dS} \cdot \mathrm{m}^{-1}$, PST $<15, \mathrm{pH} \leq 8,5$, correspondendo a 9,09\% do total da área em estudo se caracterizando como salino;

- 02 pontos de amostragem: $\mathrm{CE}_{\mathrm{ES}}<4 \mathrm{dS} \cdot \mathrm{m}^{-1}$, PST $>15, \mathrm{pH} \leq 8,5$, correspondendo a 3,03\% do total da área em estudo se caracterizando como sódico; e

- 11 pontos de amostragem: $\mathrm{CE}_{\mathrm{ES}}>4 \mathrm{dS} \cdot \mathrm{m}^{-1}$, PST $>15, \mathrm{pH} \leq 8,5$, correspondendo a 16,67\% do total da área em estudo se caracterizando como salino-sódico.

Verifica-se, portanto, que aproximadamente 28,79\% de toda área em estudo já se encontra afetada por sais. Essa área em degradação corresponde, quase que totalmente, ao setor que há mais tempo se irriga, comprovando, portanto, que a aplicação da irrigação contribui para o avanço da salinização do solo e, consequentemente, em longo prazo, para perda total da capacidade de produção, se nenhum manejo para recuperação for adotado, conforme Richards, 1974; Bernardo, 1995 e Holanda \& Amorim, 1997.

\section{CONCLUSÕES}

Na caracterização dos solos verificou-se que 28,79\% da área estudada se encontrava afetada por sais, dos quais 9,09 \% da área apresenta caráter salino, 3,03\% sódico; e 16,67\% salino-sódico.

Os setores há mais tempo irrigados apresentaram valores para $\mathrm{CE}_{\mathrm{ES}}$, PST e RAS superiores aos dos setores nunca antes irrigados. Na área estudada predomina a textura FrancoArenosa (57,20\%), que apresenta certa homogeneidade granulométrica nas quatro camadas estudadas.

A taxa média de infiltração de água no solo nunca antes irrigado apresentou valor 0,596 cm.(min.) $)^{-1}$ ou $35,76 \mathrm{~cm} \cdot \mathrm{h}^{-1}$, compatível com o padrão estabelecido para os solos de aluviais. Dessa forma, esse solo foi classificado como solo de permeabilidade moderadamente rápida a rápida e de alta permeabilidade. 
Apesar de parte da área estudada já apresentar considerável grau de afetação salina, poderá, ainda, ser utilizada para fins agrícolas desde que sejam utilizadas culturas resistentes à salinidade e técnicas de irrigação e de manejo do solo adequadas.

\section{REFERÊNCIAS BIBLIOGRÁFICAS}

BERNARDO, S. Manual de irrigação. 6ed. Viçosa; Universidade Federal de Viçosa, 1995.

CARVALHO, O. Plano integrado para o combate preventivo aos efeitos das secas no Nordeste. Brasília-DF, 1973. (Minter, série Desenvolvimento Regional, 1)

EILERS, R. G. Salinization of soil. Soil health. 1995. Disponível na internet. http://res.agr.ca/CANSIS/PUBLICATIONS/HEALTH/chapter08.html. 16/11/2000.

EMPRESA BRASILEIRA DE PESQUISA AGROPECUÁRIA - EMBRAPA. Manual de métodos de análises de solos. Serviço Nacional de Levantamento e Conservação de Solos. Rio de Janeiro, 1979.

EMPRESA BRASILEIRA DE PESQUISA AGROPECUÁRIA - EMBRAPA. Manual de métodos de análises de solo. 2ed, Rio de Janeiro. Ministério da Agricultura e do Abastecimento - Centro Nacional de Pesquisas de Solos, 1997.

HANSON, B.; GRATTAN, S. R.; FULTON, A. Agricultural salinity and drainage: A handbook for water managers. Water management. University of California Irrigation Program, University of California, 1993. Disponível na internet.

http://energy.ca.gov/agprogram/aeaptext/pubs/salinity.htm. 22/03/2000.

HOLANDA, J. S. Manejo de solo salino-sódico na região do baixo Açu - RN. Piracicaba, 1996. Escola Superior de Agricultura Luiz de Queiroz, 1996. 84p.

HOLANDA, J. S. \& AMORIM, J. R. A. Qualidade da água para irrigação. Manejo e controle da salinidade na agricultura irrigada. In: Congresso Brasileiro de Engenharia Agrícola, 26. Campina Grande, 1997. 33p.

HOLANDA, J. S. Manejo e utilização de áreas salinizadas do vale do Açu. Banco do Nordeste. Fortaleza, 2000. 95p.

INSTITUTO BRASILEIRO DE GEOGRAFIA E ESTATÍSTICA - IBGE. Atlas nacional do Brasil: Região Nordeste. Rio de Janeiro, 1985.

INSTITUTO DE DESENVOLVIMENTO DO MEIO AMBIENTE - IDEMA - RN. Informativo Municipal de Afonso Bezerra-RN. Natal, 1999. V.5. p.1.

KOTUBY-AMACHER, J.; KOENIG, R. \& KITCHEN, B. Salinity and plant tolerance. Utah State University Extention - Electronic Publishing. AG-SO-03, 8pp. 1997. Disponível na internet. $\quad \underline{\text { http://psb.usv.edu/ tal/pages/koenig/publications.html. }}$ 22/03/2000.

MALAVOLTA, E. Manual de química agrícola. nutrição de plantas e fertilidade do solo. São Paulo, Agronômica Ceres, 1976.

NEEDHAM, J. Science and civilization in China. part II: Agriculture, By Francesca Bray. Cambridge University Press, 1984. 126p.

OLIVEIRA, M. Gênese, classificação e extensão de solos afetados por sais. Manejo e controle da salinidade na agricultura irrigada. In: CONGRESSO BRASILEIRO DE ENGENHARIA AGRÍCOLA, 26. 1997. Campina Grande-PB. Anais: Campina Grande, 1997.

PEREIRA, J. \& COBBE, R. V. Fertilização, correção da acidez e da salinidade dos solos. Recomendações para os perímetros irrigados do Alto e Médio São Francisco. Brasília, Assistência Técnica ao Programa de Irrigação do Alto e Médio São Francisco, 1990. (Boletim Técnico, 1). 
QUEIROZ, J. E. Avaliação e monitoramento da salinidade do solo. Manejo e controle da salinidade na agricultura irrigada. In: CONGRESSO BRASILEIRO DE ENGENHARIA AGRÍCOLA, 26. 1997. Campina Grande, Anais: Campina Grande. 1997. 69-111p.

RAIJ, B. van. Fertilidade do solo e adubação. São Paulo, Agronômica Ceres. 1991.

RICHARDS, L. A. Diagnostico y rehalitacion de suelos salinos y sódicos. Mexico, Editorial Limusa. 1974.

ROBINSON, H. Estudio cientifico del suelo. 2ed. Madrid, Aguilar. 1953.

SCHERER, T. F.; SEELIG, B. \& FRANZEN, D. Soil, water and plant characteristics important to irrigation. February 1996. North Dakota State University. NDSU Extension Service. Disponível na Internet. http://www.ext.nodak.edu/extpubs/ageng/irrigate/eb66w.htm. 11/07/2000.

SECRETARIA DE RECURSOS HÍDRICOS DO ESTADO DO RIO GRANDE DO NORTE - SERHID. Plano estadual de recursos hídricos. Natal, 1997. Relatório de caracterização do regime hidrometeorológico das bacias. v. 1, HE-1358-R08-1298. Hidroservice, Abril/1997.

SECRETARIA DE RECURSOS HÍDRICOS DO ESTADO DO RIO GRANDE DO NORTE - SERHID. Plano estadual de recursos hídricos. Natal, 1998. Caracterização hidrogeológica dos aqüíferos do Rio Grande do Norte. HE-1358-R11-0698. Hidroservice, Junho/1998.

WITHERS, B. \& VIPOND, S. Irrigation: design and practice. B. T. Batsford Limited. London, 1974.

YAP-SALINAS, L. H. \& BRITO, R. A. L. Impactos físicos prováveis e considerações sobre uma política de manejo para o projeto de irrigação do Baixo Açu. In: SIMPÓSIO BRASILEIRO SOBRE O TRÓPICO SEMI - ÁRIDO, 1. 1982. Olinda PE. Anais: Olinda, 1982. 